\title{
The basal speed of valley glaciers: an inverse approach
}

\author{
MARTIN TRUFFER \\ Geophysical Institute, University of Alaska Fairbanks, 903 Koyukuk Drive, Fairbanks, Alaska 99775-7320, U.S.A. \\ E-mail:truffer@gi.alaska.edu
}

\begin{abstract}
Geophysical inverse methods are used to calculate the basal motion of a glacier. They are applied to a one-dimensional forward model that can be linearized to make the analysis simpler. The inverse method finds a solution that fits the data within a given error. It selects for smooth solutions to discriminate against unrealistic oscillations. The method is applied to a simple model glacier of uniform shape and thickness to test how well a given basal motion field can be reconstructed. It shows, as expected, that optimizing for smoothness lowers maxima and increases minima of the solution. A step change in basal velocity is drawn out in the inversion over a distance that is given by the half-width of a resolving function. This is typically about three times the ice thickness, but is also affected by the sampling rate of the data. The method is then applied to two glaciers where suitable data are available: Brown Glacier on Heard Island, southern Indian Ocean, and McCall Glacier in the Brooks Range, Alaska, U.S.A. The McCall results agree well with earlier estimates of basal motion.
\end{abstract}

\section{INTRODUCTION}

Modeling the flow of ice is central to glaciology. A glacier model can be used to predict changes in response to climate change (e.g. Oerlemans and Van der Veen, 1984). Inversely, observed changes of glaciers and ice sheets are related to the climate history, but the dynamics of glacier flow makes this relationship complex. Accurate glacier models are also important to help date and interpret ice cores (e.g. DahlJensen, 1989) or to assess glacier-related natural hazards (e.g. Pralong and others, 2003).

A temperate glacier can be modeled by considering the equations of mass and momentum balance, a flow law and boundary conditions (e.g. Hutter, 1983). The surface boundary condition is that of a stress-free surface and a prescribed climate (accumulation/ablation). The bottom boundary condition consists of a melting rate defining the velocity component perpendicular to the bed, and a sliding law defining the basal velocity, often as a function of the basal shear stress and/or basal water pressure (e.g. Budd and others, 1979).

Formulating a glacier flow model poses many challenges, but one of the most fundamental is a poor understanding of the basal boundary condition. This is a significant problem, because basal motion can be $50 \%$ or more of the total glacier or ice-stream motion. Direct measurements of basal motion are often difficult or impossible to obtain, for obvious reasons. Theoretical sliding laws for ice overlying bedrock have been derived (Lliboutry, 1968; Kamb, 1970; Nye, 1970; Iken, 1981; Fowler, 1986; Truffer and Iken, 1998), but they do not perform well on a macroscopic scale (e.g. Iken and Truffer, 1997). Some observations indicate that water storage plays an important role for basal motion (Kamb and others, 1994; O’Neel and others, 2001), but no useful parameterization of this relationship has yet been proposed. An added complication is that many glaciers rest on sediments. Viscous models of sediment deformation lead to basal boundary conditions similar to the ones mentioned above (Boulton and Hindmarsh, 1987), but laboratory experiments show a strongly non-linear or even plastic behavior (e.g. Kamb, 1991), which motivated Truffer and others (2001b) to introduce a stress boundary condition into their flow model. Usually it is not even possible to infer the subglacial morphology (hard vs soft vs mixed beds), but, even if that was known, there are no appropriate general boundary conditions.

Contrary to the situation at the bottom of a glacier, measurements on the glacier surface are much easier to accomplish, either by field or remote-sensing methods. In particular, synthetic aperture radar (Goldstein and others, 1993) has made it possible to measure the surface velocity fields of glaciers (Fatland and Lingle, 1998; Michel and Rignot, 1999) and large parts of the ice sheets (Fahnestock and others, 1993; Joughin and others, 1996, 1999, 2000; Rignot and others, 1997, 2001; Mohr and others, 1998). Airborne and ground geophysics also provide an increasing dataset of ice thickness and surface topography (Bamber and others, 2001a, b; Gogenini and others, 2001; Lythe and others, 2001; Arendt and others, 2002).

Mathematically, this sets up a classic ill-posed problem: it can be shown that infinitely many assumptions for the basal velocity field lead to the same surface velocities. Essentially, there are too many boundary conditions at the top and not enough at the bottom. This situation is common in many other areas of science, particularly geophysics. It is typically addressed by inverse methods.

Inverse theory is becoming an increasingly popular tool in glaciology. Van der Veen and Whillans (1989) pioneered the force budget method. It uses geometry and surface velocities as input and calculates basal velocities by solving the momentum equations in successive layers from the top down. This method is numerically unstable, however, and it magnifies input errors (Bahr and others, 1994; Lliboutry, 1995). It lacks the capability to deal with errors in the input 
data, and it provides no mechanism to choose a desirable solution among the infinitely many possible solutions. On the other hand, the force budget method works well for estimating basal shear stresses on the scale of several ice thicknesses.

MacAyeal (1993) applied control theory to calculate the basal friction of Ice Stream E, West Antarctica. He solves a well-posed forward model assuming some basal friction. The friction is then used as an adjustable parameter to minimize a misfit functional (calculated vs observed surface velocities) using an adjoint trajectory method. This theory is robust and has also been successfully applied to West Antarctica's Whillans Ice Stream (Rommelaere and MacAyeal, 1997) and the northeast Greenland ice stream (Joughin and others, 2001), where a finite-element forward model (MacAyeal, 1989; Hulbe and MacAyeal, 1999) was inverted. Gudmundsson and others (1998) chose an analytical approach and calculated transfer functions for basal velocities and topography, and inverted those.

Here we propose to use a different approach, based on inverse methods common in geophysics and many other areas (Menke, 1989; Parker, 1994).

\section{METHODS}

In this paper we will adapt textbook inverse methods to an analytical one-dimensional glaciological model developed by Kamb and Echelmeyer (1986). It is particularly simple, because it can be linearized. We will follow an approach outlined by Parker (1994, section 3).

The first step in inverse modeling is the formulation of a forward model. A forward model is a well-posed problem; in our case it is a model to calculate surface velocities, given an appropriate basal boundary condition (such as basal velocities). In general terms, a linear forward model can be written as an inner product:

$$
d_{j}=\left(g_{j}, m\right), j=1 . . N,
$$

where $d_{j}$ are $N$ numbers that can be derived from measurements taken at discrete points, $x_{j}$. The so-called model $m$ is a continuous function of the longitudinal coordinate $x$ and $g_{j}$ are continuous functions of $x_{j}-x$, called representers. Equation (1) defines a linear forward model. If $m$ is known, $d_{j}$ can be calculated. The inverse model finds $m$ given $d_{j}$. If we treat $m$ as a function in a Hilbert space $V$, and $d_{j}$ are $N$ real numbers, then the inverse problem is underdetermined and infinitely many exact solutions exist for $m$. The goal then is to find a measure of $m$ to optimize, so the best solution in some sense can be selected. We will choose a norm (actually a semi-norm) based on the first derivative. This procedure will select for a smooth solution, i.e. one with a small first derivative. Even though the data can be fitted exactly, it is advantageous to relax this criterion. The data will only be fitted within a given tolerance.

As an example we will present a one-dimensional forward model that can be linearized. It treats the flow of glacier ice down an inclined channel. An analytical solution exists for the surface velocity of an inclined slab (inclination $\alpha$, thickness $h$ ) of infinite extent (Paterson, 1994):

$$
u_{\text {plate }}=\frac{2 A}{n+1}(\rho g \sin \alpha)^{n} h^{n+1},
$$

where $u_{\text {plate }}$ is the surface speed. Equation (2) is derived by treating ice as a non-linear viscous fluid: $A$ is the flow rate factor, $n$ the flow law exponent, $\rho$ the ice density and $g$ the gravitational acceleration. For flow of ice confined to a channel the surface velocity on the center line of the glacier can be calculated by introducing a shape factor $f$ (Nye, 1965):

$$
u_{\mathrm{ch}}=\frac{2 A}{n+1}(\rho g f \sin \alpha)^{n} h^{n+1} .
$$

$h$ is now the ice thickness at the center of the channel. Kamb and Echelmeyer (1986) described a method to calculate $u_{\mathrm{ch}}$ for the case of longitudinally variable ice thickness and surface slope, by a method of longitudinal averaging (adapted from their equations $35 \mathrm{a}$ and $\mathrm{b}$ ):

$$
\ln u_{\text {surf }}(x)=\int_{0}^{L} g\left(x^{\prime}-x\right) \ln \left(u_{\mathrm{ch}}\left(x^{\prime}\right)+u_{b}\left(x^{\prime}\right)\right) \mathrm{d} x^{\prime}
$$

where $x$ is the downslope longitudinal coordinate, $L$ is the glacier's length, and $g($.$) is a weighing function:$

$$
g\left(x-x^{\prime}\right)=C \mathrm{e}^{-\left|x-x^{\prime}\right| / L_{+,-}} .
$$

$C$ is a normalizing factor such that $\int_{0}^{L} g\left(x^{\prime}-x\right) \mathrm{d} x^{\prime}=1 . \mathrm{L}_{-}$ and $\mathrm{L}_{+}$are up- and downstream averaging lengths, as calculated by Kamb and Echelmeyer (1986). They are typically about three times the local ice thickness. The basal speed $u_{\mathrm{b}}$ was introduced into Equation (4) in an ad hoc way, assuming that it is averaged in the same way as the deformational speed $u_{\mathrm{ch}}$. It is of advantage to write Equation (4) as an inner product:

$$
\ln u_{\text {surf }}=\left[g, \ln \left(u_{\mathrm{ch}}+u_{\mathrm{b}}\right)\right] .
$$

We recast this equation into:

$$
\ln u_{\text {surf }}-\left(g, \ln u_{\mathrm{ch}}\right)=\left[g, \ln \left(1+\frac{u_{\mathrm{b}}}{u_{\mathrm{ch}}}\right)\right] .
$$

The lefthand side can be evaluated at discrete points $x_{j}$, as it only contains quantities derivable from measurements, such

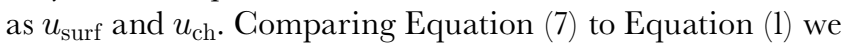
realize that we have defined a linear inverse problem, with $d_{j}=\ln u_{\text {surf }}\left(x_{j}\right)-\left(g, \ln u_{\mathrm{ch}}\right)$ and $m=\ln \left(1+u_{\mathrm{b}} / u_{\mathrm{ch}}\right)$.

As mentioned above, infinitely many solutions $m$ satisfy Equation (7) exactly. We now need a measure to choose an optimal solution. Following Parker (1994, sec. 3.05), we accomplish this by minimizing a norm. The choice of a norm should be guided by a property of the function that is desirable. Here, we choose a norm (more correctly a semi-norm) that is a measure of the first derivative of $m$. Minimizing this norm will select a function with a small first derivative, i.e. a smooth function. Since solutions will be found numerically, we proceed by discretizing $m$, writing it as a vector in $\mathbb{R}^{M}$, with $M>N$ (the number of measurements). The calculation of the norm can then be defined through a matrix $R$, such that:

$$
\|m\|^{2}=m R^{T} R m .
$$

We will choose $R=W^{1 / 2} \partial$, where $W^{1 / 2}=\operatorname{diag}\left(w_{1}^{1 / 2}, w_{2}^{1 / 2}\right.$, $\left.\ldots, w_{N}^{1 / 2}\right)$ is a diagonal matrix containing the proper weighting factors for a quadrature rule integration, and

$$
\delta=\frac{1}{h}\left[\begin{array}{cccccc}
0 & & & & & \\
-1 & 1 & & & 0 & \\
& -1 & 1 & & & \\
& & & \ldots & & \\
& 0 & & -1 & 1 & \\
& & & & -1 & 1
\end{array}\right]
$$

is a differencing operator. It is now possible to proceed by 


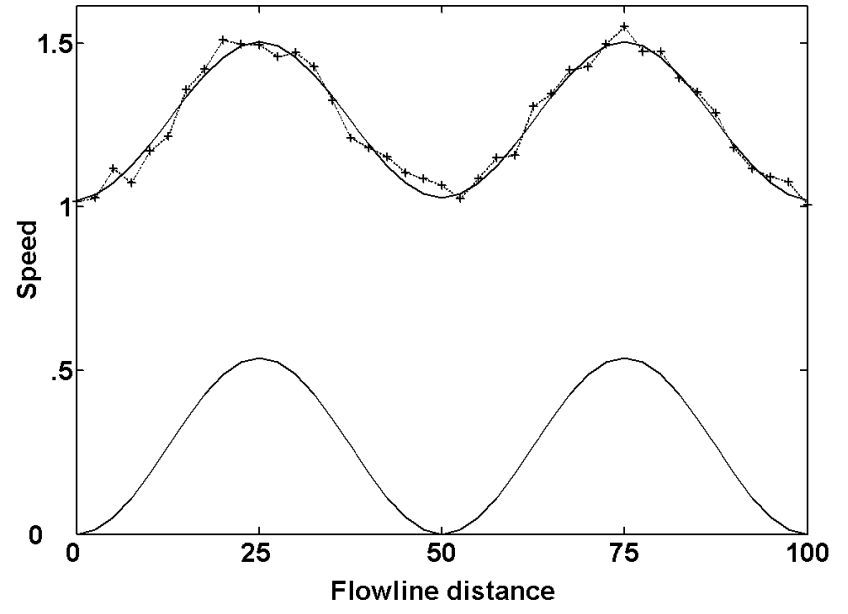

Fig. 1. A forward model is used to generate "data". The lower line is the prescribed basal speed, the upper solid line shows calculated surface speed, and the crosses show the surface speed with some random noise that is used for the inverse model. The longitudinal coordinate is normalized by the ice thickness, and the flow speed by the deformational speed that would result if the glacier was frozen to its bed.

minimizing this norm for all $m$ that solve Equation (7) exactly.

However, the lefthand side of Equation (7) has measurement errors associated with it, so we do not wish to solve it exactly. Instead, we require that Equation (7) be solved within a tolerance that is dictated by the errors in the data:

$$
\left\|\Sigma^{-1}(d-B m)\right\| \leq T,
$$

where $\Sigma$ is a diagonal matrix containing the standard deviations, and $B=W G$ is the product of a weighting matrix for quadrature integration $W$ and the Gram matrix $G$ consisting of the discretized representers $g_{j} . T$ is the tolerance level, and it is strictly a function of $N$ (Parker, 1994, sec. 3.01). Parker (1994, sec. 3.02) also shows that under most conditions equality holds for Equation (10). The problem now becomes one of minimizing the semi-norm (6) under condition (10). A standard method of doing that is to introduce a Lagrange multiplier $\nu$ and minimize the functional:

$$
U(m, \nu)=m R^{T} R m-\nu\left(T^{2}-\|\Sigma(d-B m)\|^{2}\right) .
$$

$\nu$ is sometimes called the trade-off parameter. If it is large, fitting the data within the tolerance is dominant; if it is small, then minimizing the semi-norm is more important. In that sense it defines a trade-off between norm-minimization and data fit. But in general, both $\nu$ and $m$ can be found by solving $\partial U / \partial m_{i}=0$ and $\partial U / \partial \nu=0$. The second condition simply yields Equation (10) with equality.

\section{SYNTHETIC GLACIERS}

We have done controlled tests of this inverse procedure by running a forward model to create "data", introducing some noise, and inverting the "data". The forward model consists of a simple glacier of uniform thickness, shape and slope. The basal speed varies down-glacier (lower curve in Fig. 1). The upper solid line shows the surface speed predicted by the forward model. We then sample this at regular intervals and introduce random noise (crosses in Fig. 1). This "dataset" is used as an input to the inverse model.

The lower solid line in Figure 2 shows the results of the

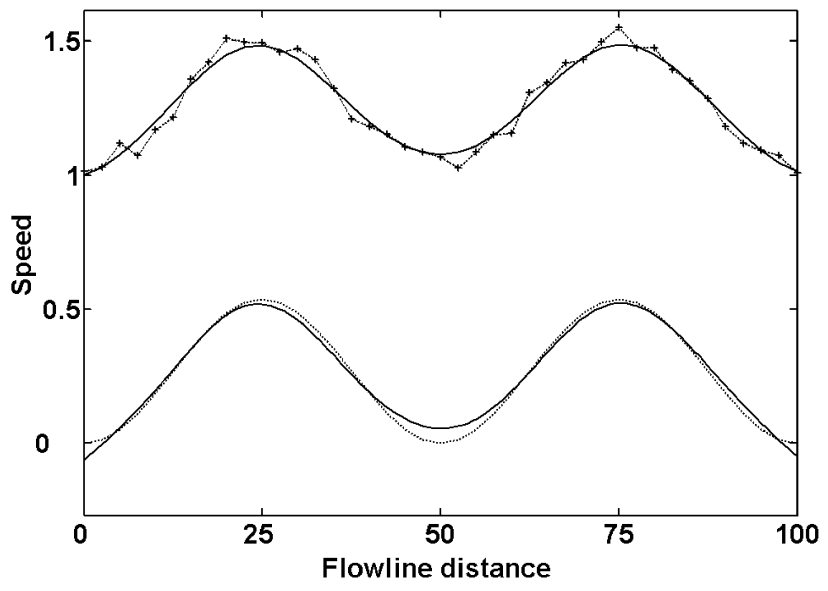

Fig. 2. Results of the inversion (lower solid line) compared to the originally prescribed basal speed. The inversion result is again run through the forward model (upper solid line) and compared to the "data". Normalized units are as in Figure 1.

inversion, compared to the originally prescribed basal speed (lower dotted line). The basal speeds resulting from the inversion are again run through the forward model (upper solid line) and compared to the "data". This simple example shows that a satisfactory solution can be found. Because the inverse procedure selects smooth functions, the true maxima in basal speed are under-predicted while the minima are over-predicted. Figure 2 also shows that the solution fits the data within the error.

Two things should be noted: First, in general the true basal velocities cannot be recovered. This is because of the diffusive nature of ice flow. Small-scale velocity variations can only be detected close to the glacier bed, not at the surface. This is in close agreement with results from Balise and Raymond (1986) and Gudmundsson (2003). Secondly, it would be a mistake to try to fit surface velocities exactly. Of all the models that fit the above "data" exactly (there are an infinity), the smoothest one still oscillates in an unrealistic fashion (Fig. 3). This is again due to the non-linear and diffusional nature of ice flow. If an error in a surface measurement is interpreted as a physical effect described by the model, it will require an amplified subglacial cause. This is a

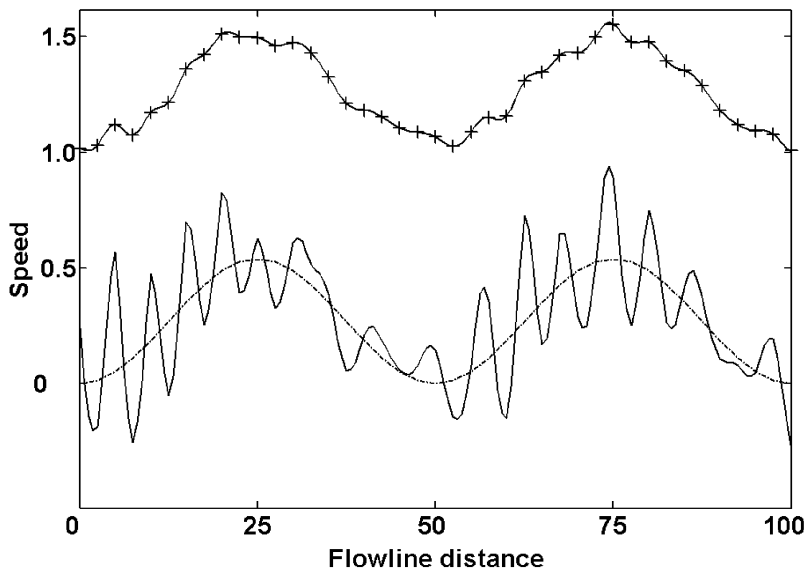

Fig. 3. The smoothest model that fits the "data" exactly. The lower curve shows the result of the inversion (solid line) compared to the originally prescribed basal speed (dotted line). The upper curve shows the "data" (crosses) and the fit of the inversion to them (solid line). Units are as in Figure 1. 


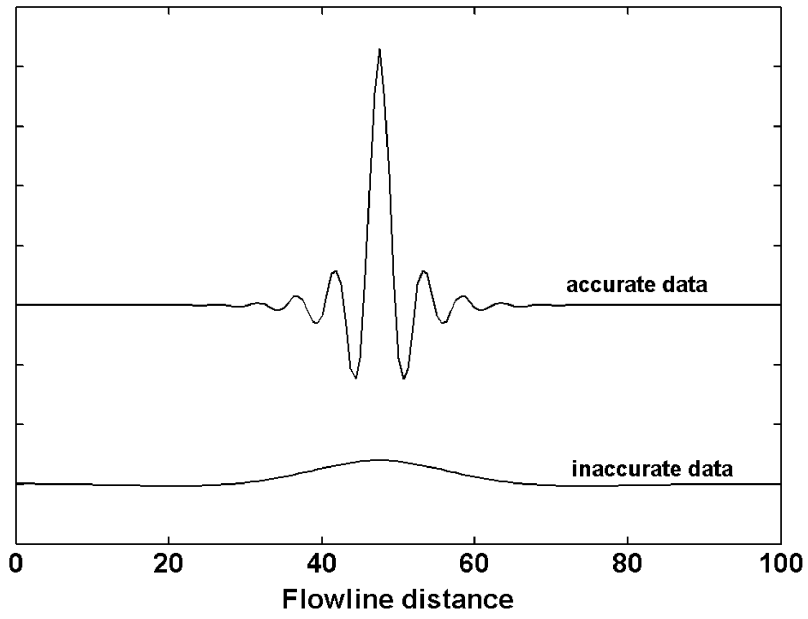

Fig. 4. Resolving function for the inversion discussed above (upper line). The half-width of this function defines a resolving scale for the inverse model. The lower line illustrates how the resolution degrades for inaccurate data.

major problem with Van der Veen and Whillans' (1989) force budget method. It is an appealing feature of this inverse method that measurement errors can be accommodated.

As mentioned above, we cannot hope to resolve velocity variations on a small scale. There is a somewhat intuitive way to derive resolving functions to find the minimum resolving length. It is done by running a Dirac function through the forward model and then inverting the result. The Dirac $\delta$ function is used, because it represents the smallest possible perturbation. Inverting the resulting surface speeds thus illustrates how much a small-scale basal perturbation spreads through the inversion process. The halfwidth of the resulting bell-shaped function gives a measure of the spatial scale at which structure in the model can be resolved (Fig. 4). This scale depends on the accuracy of the data. It is noteworthy that the resolving scale does not tend towards zero as the sampling interval for the data becomes small. The half-width of the resolving function remains at two to three ice thicknesses, even for an almost continuous record of glacier geometry and surface speed (Fig. 4; ice thickness is $200 \mathrm{~m}$ in this example).

Since the inversion method presented here selects for a smooth model, it will discriminate against fast changes and spread them out over a range given approximately by the half-width of the resolving function. We illustrate this by modeling a glacier with constant thickness $(200 \mathrm{~m})$, slope $\left(5^{\circ}\right)$, and channel shape $(f=0.5)$. Basal velocities undergo a step change from 0 to $5 \mathrm{~m} \mathrm{a}^{-1}$ halfway down the glacier. We ran the forward model and inverted it subsequently (Fig. 5). The step change is spread over several ice thicknesses, as illustrated by the results of the inversion and the resolving function.

We will now apply the method to two glaciers, where suitable data have been gathered: Brown Glacier in the southern Indian Ocean, and McCall Glacier in the Brooks Range, Alaska, U.S.A.

\section{BROWN GLACIER}

Brown Glacier is located on the flanks of Big Ben, a $2700 \mathrm{~m}$ high volcano on the Australian sub-antarctic Heard Island $\left(53^{\circ} 05^{\prime} \mathrm{S}, 73^{\circ} 30^{\prime} \mathrm{E}\right)$. The Australian Antarctic Division

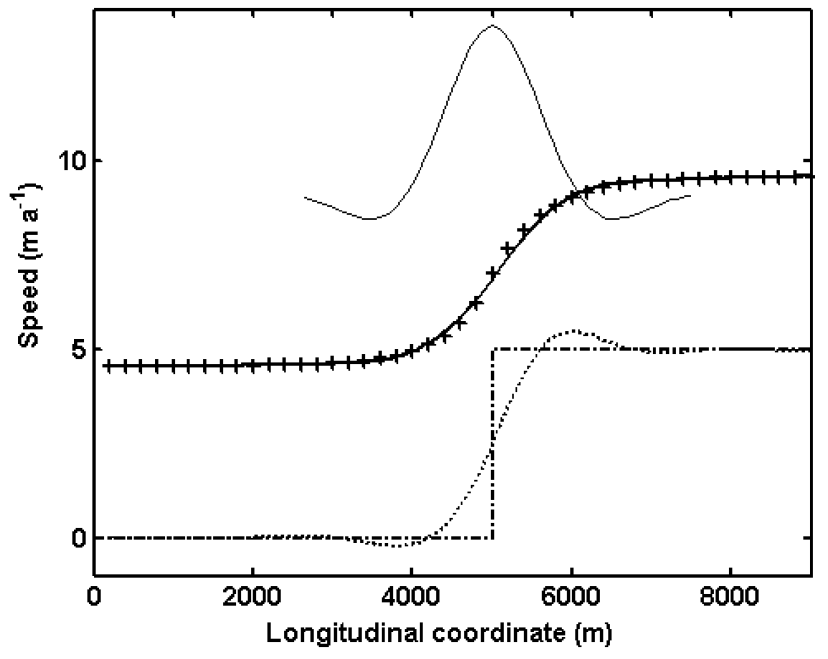

Fig. 5. A step change (dash-dotted line) in basal speed was run through the forward model and sampled at a regular interval (crosses). The results were then inverted (dotted line). The inversion results fit the original data well (thick solid line). The half-width of the resolving function (thin solid line) compares well to the spreading of the step change in the inversion process.

selected it for a detailed study illustrating glacier change in the Southern Hemisphere. The ensuing report (Truffer and others, 2001a) contains data on the flow and geometry of the glacier (Fig. 6). Velocities were measured at points spaced about $500 \mathrm{~m}$ along the $5 \mathrm{~km}$ long glacier (Fig. 6d). Ice thickness was only measured at four sites (Fig. 6a). The shape factor was calculated assuming a channel of parabolical shape and interpolating between the results obtained for the halfwidth to depth ratios calculated by Nye (1965). Surface slope was read from a map that was created from kinematic global positioning system profiles (Truffer and others, 2001a). The slope was averaged over about one ice thickness $(\sim 100 \mathrm{~m})$.

We restrict our analysis to the lower part of the glacier, where the ice thickness is known. All data were interpolated

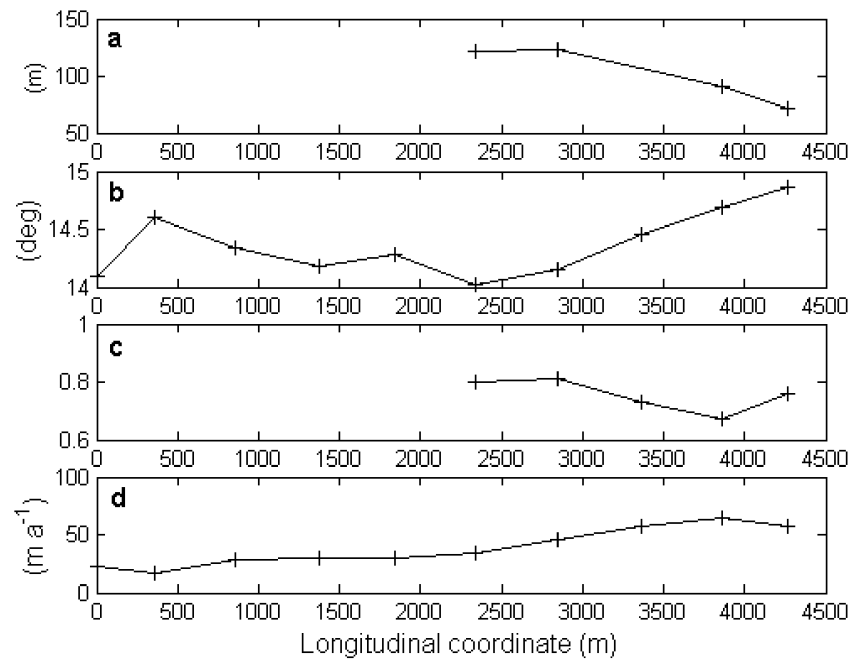

Fig. 6. Data used in the inverse model for Brown Glacier. Ice thickness (a), surface slope (b), shape factor (c) and observed surface velocities $(d)$ are shown. Ice thickness and shape factors were only determined on the lower part of the glacier. 


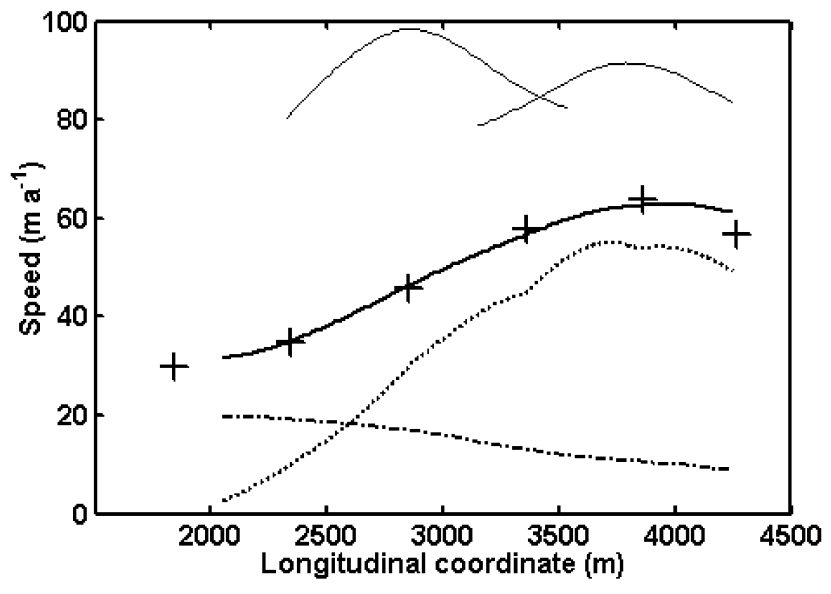

Fig. 7. Results of the Brown Glacier inversion, showing the inverted basal speed (dotted line), the deformational speed without basal motion (dash-dotted line), the surface speed calculated from the inverted results (solid line), and the observed speed (crosses). Note that the results of the inversion do not match the observations exactly. The bell-shaped curves are resolving functions at two positions. Their half-width is an indication of the spatial scale over which changes can be resolved.

onto a regular grid, spaced $200 \mathrm{~m}$, and this was used as an input for the inverse model, as described above. We assumed a flow rate factor of $A=3.2 \times 10^{-24} \mathrm{~Pa}^{-3} \mathrm{~s}^{-1}$ in Equation (1). This value is about half that recommended by Paterson (1994). Figure 7 shows the deformational speed calculated with the forward model assuming no basal motion. Note that the deformational speed would exceed observed surface speed at many locations if Paterson's (1994) value for the flow rate factor were used. This has been found to be true for many temperate glacier flow models (Hooke, 1981; Hubbard and others, 1998; Gudmundsson, 1999; Adalgeirsdóttir, 2000; Albrecht and others, 2000; Truffer and others, 2001b). The inversion indicates steadily increasing basal motion in the lower part of the glacier (Fig. 7). As discussed above, we do not require the inversion to fit the data exactly, in order to account for errors. The actual measurement errors for the glacier speed are small $\left( \pm 3 \mathrm{~m} \mathrm{a}^{-1}\right)$, but additional errors can arise due to the simplification of a one-dimensional model. Figure 7 also shows the fit of the inversion to the original data, and resolving functions at two points. These functions have a half-width of about $500 \mathrm{~m}$. This defines a useful scale for the interpretation of the inversion results. Nothing should be deduced on a scale smaller than that. For example, it is possible that the actual increase in basal motion happens on a smaller scale, as demonstrated above for the step function model.

\section{McGALL GLAGIER}

McCall Glacier in Alaska's Brooks Range has been studied intermittently since the International Geophysical Year (Rabus and others, 1995, and references therein). As part of a more recent regional mass-balance study, Rabus and Echelmeyer (1997) described the dynamics of this polythermal glacier. They noticed that deformational speeds alone could not account for the observed surface speeds and a region of year-round basal motion must exist in the middle part of the glacier. Here, we confirm their findings by run-

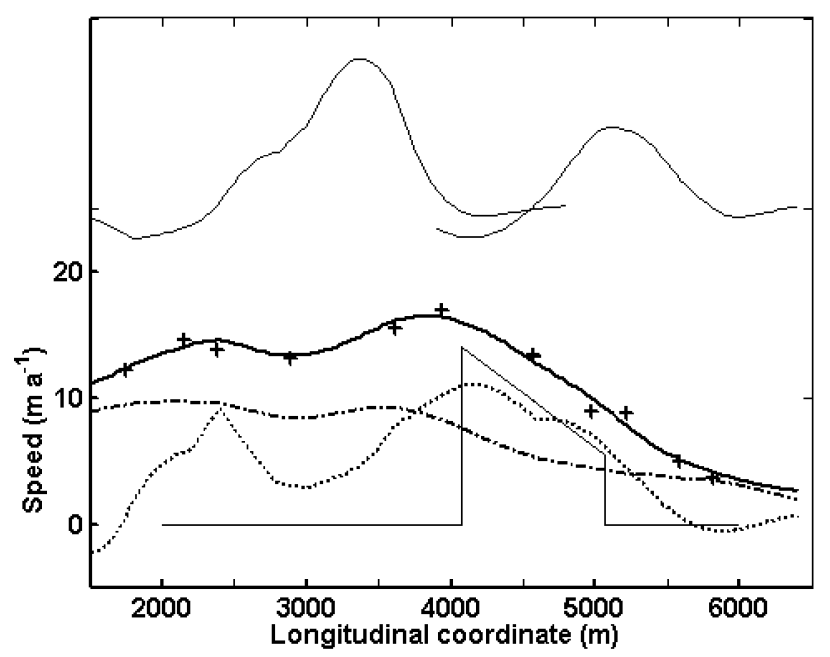

Fig. 8. Results of the McCall Glacier inversion. Inverted basal motion (dotted line), deformational speed (dash-dotted line), surface speed calculated from the inversion results (heavy thick line), and the observed surface speeds (crosses) are shown. The thin solid line shows the basal velocity that Rabus and Echelmeyer (1997) used to model surface velocities. The bell-shaped curves are resolving functions with half-widths of about $700 \mathrm{~m}$ (four to five ice thicknesses).

ning an inverse model. We used data published by the above authors (their fig. 10) and sampled it every $200 \mathrm{~m}$. Our results show not only the sliding anomaly pointed out by Rabus and Echelmeyer (1997), but also a smaller one further upstream (Fig. 8). Not surprisingly, the inversion results in a smoother profile of basal speeds than that proposed by the other authors. The resolving functions show a resolving scale of about $500-700 \mathrm{~m}$ (or about three to four times the ice thickness). As discussed above, nothing can be said about the variation of basal motion on smaller scales, so both models for basal motion are equally plausible.

\section{GONGLUSIONS}

We successfully applied geophysical inverse methods to find the basal velocity of a valley glacier. The forward model is a one-dimensional theory of glacier flow down an inclined channel. It includes longitudinal stress gradients (Kamb and Echelmeyer, 1986) and can be used to calculate the surface speed given the glacier geometry, basal motion and the flow law. Inverse methods are then applied to calculate the basal motion, given the surface speed and glacier geometry, which is a more realistic and common situation. The inverse procedure chosen here selects for a smooth model by minimizing a norm that is a measure of the first derivative. In general, the inverse problem can be solved exactly. However, it is advantageous to relax that condition and allow the model to account for errors in the data. This prevents unphysical solutions resulting from trying to fit measurement errors, or processes not accounted for in the model. Our method also allows us to calculate so-called resolving functions. They are obtained by propagating a point perturbation through the forward and back through the inverse model. Its half-width is a qualitative measure of the minimum scale that can be resolved by the inverse method. This scale is typically three to four times the ice thickness, but can be larger if data are sparse. It depends on the averaging lengths $\left(L_{+}\right.$and $L_{-}$in Equation $\left.(5)\right)$ and on the sampling 
interval for geometry and surface velocity. The averaging lengths also depend on the rate of basal motion (Kamb and Echelmeyer, 1986). This can be accounted for through an iterative procedure, where the averaging lengths are adjusted after a first inversion, and the inversion is then repeated with the new values.

This paper focuses on applying inverse methods to valley glacier flow, which is a problem that has seldom been addressed in the glaciological inverse literature. However, the same methods can be applied to ice sheets and ice streams, and they can be generalized, in principle, to non-linear forward models (e.g. Parker, 1994) and to numerical forward models. They can then be extended to two or three dimensions and applied to a variety of complex flow regimes.

\section{ACKNOWLEDGEMENTS}

I would like to thank K. Echelmeyer who sparked my interest in these methods and with whom I had many fruitful discussions. I also appreciate the input from R. Greve (Scientific Editor), H. Blatter and an anonymous reviewer. M. Lüthi read the manuscript and provided useful comments. Part of this work was done while working at the Australian Antarctic Division in Hobart, Tasmania. Funding from the U.S. National Science Foundation (OPP-0115819) helped complete the study.

\section{REFERENGES}

Aðalgeirsdóttir, G., G. H. Gudmundsson and H. Björnsson. 2000. The response of a glacier to a surface disturbance: a case study on Vatnajökull ice cap, Iceland. Ann. Glaciol., 31, 104-110.

Albrecht, O., P. Jansson and H. Blatter. 2000. Modelling glacier response to measured mass-balance forcing. Ann. Glaciol., 31, 91-96.

Arendt, A. A., K. A. Echelmeyer, W. D. Harrison, C. S. Lingle and V. B. Valentine. 2002. Rapid wastage of Alaska glaciers and their contribution to rising sea level. Science, 297(5580), 382-386. (Tables and figures at www.sciencemag.org/cgi/content/full/297/5580/382/DCl.)

Bahr, D. B., W.T. Pfeffer and M. F. Meier. 1994. Theoretical limitations to englacial velocity calculations. F. Glaciol., 40(136), 509-518.

Balise, M. J. and C. F. Raymond. 1985. Transfer of basal sliding variations to the surface of a linearly viscous glacier. F. Glaciol., 31 (109), 308-318.

Bamber, J. L., S. Ekholm and W. B. Krabill. 2001a. A new, high-resolution digital elevation model of Greenland fully validated with airborne laser altimeter data. 7. Geophys. Res., 106(B4), 6733-6746.

Bamber, J. L., R. L. Layberry and S. P. Gogineni. 2001b. A new ice thickness and bed data set for the Greenland ice sheet. 1. Measurement, data reduction, and errors. F. Geophys. Res., 106(D24), 33,773-33,780.

Boulton, G. S. and R. C. A. Hindmarsh. 1987. Sediment deformation beneath glaciers: rheology and geological consequences. f. Geophys. Res., 92(B9), 9059-9082.

Budd, W. F., P. L. Keage and N. A. Blundy. 1979. Empirical studies of ice sliding. F. Glaciol., 23 (89), 157-170.

Dahl-Jensen, D. 1989. Two-dimensional thermo-mechanical modelling of flow and depth-age profiles near the ice divide in central Greenland. Ann. Glaciol., 12, 31-36.

Fahnestock, M., R. Bindschadler, R. Kwok and K. Jezek. 1993. Greenland ice sheet surface properties and ice dynamics from ERS-1 SAR imagery. Science, 262(5139), 1530-1534.

Fatland, D. R. and C. S. Lingle. 1998. Analysis of the 1993-95 Bering Glacier (Alaska) surge using differential SAR interferometry. F. Glaciol., 44(148), 532-546.

Fowler, A. C. 1987. Sliding with cavity formation. f. Glaciol., 33(115), 255-267.

Gogineni, S. and 9 others. 2001. Coherent radar ice thickness measurements over the Greenland ice sheet. 7. Geophys. Res., 106(D24), 33,761-33,772.

Goldstein, R. M., H. Engelhardt, B. Kamb and R. M. Frolich. 1993. Satellite radar interferometry for monitoring ice sheet motion: application to an Antarctic ice stream. Science, 262(5139), 1525-1530.
Gudmundsson, G. H. 1999. A three-dimensional numerical model of the confluence area of Unteraargletscher, Bernese Alps, Switzerland. F. Glaciol., 45(150), 219-230.

Gudmundsson, G. H. 2003. Transmission of basal variability to a glacier surface. 7. Geophys. Res., 108(B5), 2253. (10.1029/2002JB0022107.)

Gudmundsson, G. H., C. F. Raymond and R. Bindschadler. 1998. The origin and longevity of flow stripes on Antarctic ice streams. Ann. Glaciol., 27, $145-152$.

Hooke, R. LeB. 1981. Flow law for polycrystalline ice in glaciers: comparison of theoretical predictions, laboratory data, and field measurements. Rev. Geophys. Space Phys., 19(4), 664-672.

Hubbard, A., H. Blatter, P. Nienow, D. Mair and B. Hubbard. 1998. Comparison of a three-dimensional model for glacier flow with field data from Haut Glacier d'Arolla, Switzerland. 7. Glaciol., 44(147), 368-378.

Hulbe, C. L. and D. R. MacAyeal. 1999. A new numerical model of coupled inland ice sheet, ice stream, and ice shelf flow and its application to the West Antarctic Ice Sheet. 7. Geophys. Res., 104(B11), 25,349-25,366.

Hutter, K. 1983. Theoretical glaciology; material science of ice and the mechanics of glaciers and ice sheets. Dordrecht, etc., D. Reidel Publishing Co.; Tokyo, Terra Scientific Publishing Co.

Iken, A. 1981. The effect of the subglacial water pressure on the sliding velocity of a glacier in an idealized numerical model. f. Glaciol., 27(97), 407-421.

Iken, A. and M. Truffer. 1997. The relationship between subglacial water pressure and velocity of Findelengletscher, Switzerland, during its advance and retreat. f. Glaciol., 43(144), 328-338.

Joughin, I., R. Kwok and M. Fahnestock. 1996. Estimation of ice-sheet motion using satellite radar interferometry: method and error analysis with application to Humboldt Glacier, Greenland. F. Glaciol., 42(142), 564-575.

Joughin, I. and 7 others. 1999. Tributaries of West Antarctic ice streams revealed by RADARSAT interferometry. Science, 286(5438), 283-286.

Joughin, I. R., M. A. Fahnestock and J. L. Bamber. 2000. Ice flow in the northeast Greenland ice stream. Ann. Glaciol., 31, 141-146.

Joughin, I., M. Fahnestock, D. MacAyeal, J. L. Bamber and P. Gogineni. 2001. Observation and analysis of ice flow in the largest Greenland ice stream. 7. Geophys. Res., 106(D24), 34,021-34,034.

Kamb, B. 1970. Sliding motion of glaciers: theory and observation. Rev. Geophys. Space Phys., 8 (4), 673-728.

Kamb, B. 1991. Rheological nonlinearity and flow instability in the deforming bed mechanism of ice stream motion. 7. Geophys. Res., 96(B10), $16,585-16,595$.

Kamb, B. and K. A. Echelmeyer. 1986. Stress-gradient coupling in glacier flow: I. Longitudinal averaging of the influence of ice thickness and surface slope. f. Glaciol., 32(111), 267-284.

Kamb, B., H. Engelhardt, M. A. Fahnestock, N. Humphrey, M. Meier and D. Stone. 1994. Mechanical and hydrologic basis for the rapid motion of a large tidewater glacier. 2. Interpretation. 7. Geophys. Res., 99(B8), $15,231-15,244$.

Lliboutry, L. 1968. General theory of subglacial cavitation and sliding of temperate glaciers. 7. Glaciol., 7 (49), 21-58.

Lliboutry, L. 1995. Correspondence. Why calculated basal drags of ice streams can be fallacious. F. Glaciol., 41(137), 204-205.

Lythe, M. B., D. G. Vaughan and BEDMAP Consortium. 2001. BEDMAP: a new ice thickness and subglacial topographic model of Antarctica. 7. Geophys. Res., 106 (B6), 11,335-11,351.

MacAyeal, D. R. 1989. Large-scale ice flow over a viscous basal sediment: theory and application to Ice Stream B, Antarctica. 7. Geophys. Res., 94(B4), 4071-4087.

MacAyeal, D. R. 1993. A tutorial on the use of control methods in ice-sheet modeling. F. Glaciol., 39(131), 91-98.

Menke, W. 1989. Geophysical data analysis: discrete inverse theory. Revised edition. New York, etc., Academic Press.

Michel, R. and E. Rignot. 1999. Flow of Glaciar Moreno, Argentina, from repeat-pass Shuttle Imaging Radar images: comparison of the phase correlation method with radar interferometry. f. Glaciol., 45(149), 93-100.

Mohr, J.J., N. Reeh and S. N. Madsen. 1998. Three-dimensional glacial flow and surface elevation measured with radar interferometry. Nature, 391 (6664), 273-276.

Nye, J. F. 1965. The flow of a glacier in a channel of rectangular, elliptic or parabolic cross-section. f. Glaciol., 5(41), 661-690.

Nye, J. F. 1970. Glacier sliding without cavitation in a linear viscous approximation. Proc. R. Soc. London, 315(1522), 381-403.

Oerlemans, J. and C. J. van der Veen. 1984. Ice sheets and climate. Dordrecht, etc., D. Reidel Publishing Co.

O'Neel, S., K. A. Echelmeyer and R. J. Motyka. 2001. Short-term flow dynamics of a retreating tidewater glacier: LeConte Glacier, Alaska, U.S.A. 7. Glaciol., 47(159), 567-578. 
Parker, R. L. 1994. Geophysical inverse theory. Princeton, NJ, Princeton University Press.

Paterson, W. S. B. 1994. The physics of glaciers. Third edition. Oxford, etc. Elsevier.

Pralong, A., M. Funk and M. P. Lüthi. 2003. A description of crevasse formation using continuum damage mechanics. Ann. Glaciol., 37, 77-82.

Rabus, B.T. and K. A. Echelmeyer. 1997. The flow of a polythermal glacier: McCall Glacier, Alaska, U.S.A. 7. Glaciol., 43(145), 522-536.

Rabus, B., K. Echelmeyer, D. Trabant and C. Benson. 1995. Recent changes of McCall Glacier, Alaska. Ann. Glaciol., 21, 231-239.

Rignot, E. J., S. P. Gogineni, W. B. Krabill and S. Ekholm. 1997. North and north-east Greenland ice discharge from satellite radar interferometry. Science, 276(5314), 934-937.

Rignot, E., S. Gogineni, I. Joughin and W. Krabill. 2001. Contribution to the glaciology of northern Greenland from satellite radar interferometry. F. Geophys. Res., 106 (D24), 34,007-34,019.

Rommelaere, V. and D. R. MacAyeal. 1997. Large-scale rheology of the Ross Ice Shelf, Antarctica, computed by a control method. Ann. Glaciol., 24, 43-48.

Truffer, M. and A. Iken. 1998. The sliding velocity over a sinusoidal bed at high water pressure. F. Glaciol., 44(147), 379-382.

Truffer, M., D. Thost and A. Ruddell. 200la. The Brown glacier, Heard Island: its morphology, dynamics, mass balance and climate setting. Antarct. CRCRes. Rep. 24.

Truffer, M., K. A. Echelmeyer and W. D. Harrison. 2001b. Implications of till deformation on glacier dynamics. F. Glaciol., 47(156), 123-134.

Van der Veen, C. J. and I. M. Whillans. 1989. Force budget: I. Theory and numerical methods. f. Glaciol., 35(119), 53-60.

MS received 2 August 2003 and accepted in revised form 21 December 2003 